\title{
Preliminary of Pharmacokinetics Study of Brown Seaweed (Turbinaria decurrens Bory) Extract in Colon Cancer Model Mice Induced by AOM (Azoxymethane) and DSS (Dextran Sodium Sulphate)
}

\author{
Nurul Qurrota'Ayun, Astria Deviyani Zakaria, Anton Bahtiar
}

\section{Nurul Qurrota'Ayun, Astria Deviyani Zakaria, Anton Bahtiar}

Department of Pharmacology and Toxicology, Faculty of Pharmacy, Universitas Indonesia Depok, INDONESIA.

\section{Correspondence}

\section{Anton Bahtiar}

Department of Pharmacology and Toxicology, Faculty of Pharmacy, Universitas Indonesia Depok INDONESIA

Phone no : +62-21-7864049/ +62-21-7863433

E-mail: anton.bahtiar@farmasi.ui.ac.id History

- Submission Date: 01-01-2018:

- Review completed: 12-02-2018;

- Accepted Date: 12-02-2018

DOI : 10.5530/pj.2018.3.92

Article Available online http://www.phcogj.com/v10/i3

\section{Copyright}

(c) 2018 Phcog.Net. This is an openaccess article distributed under the terms of the Creative Commons Attribution 4.0 International license.

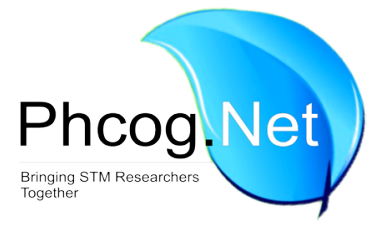

\begin{abstract}
Introduction: Colon Cancer is one of leading cancer that causes morbidity and mortality worldwide, causes 774,000 deaths. Fucoxanthin contained brown seaweed Bory) extracts showed cytotoxic activity by and study, including colon cancer. This study aims to examine the absorption profile of fucoxanthin in blood plasma on colon cancer model mice. Methods: Mice were induced by azoxymethane (AOM) and two cycle dextran sulfate sodium (DSS). Mice were given an extract of brown seaweed Bory that contain fucoxanthin. Fucoxanthin content in blood plasma analyzed using mobile phase methanol: acetonitrile by ReversedPhase High-Performance Liquid Chromatography (RP-HPLC) analysis. Results: The maximum concentration of fucoxanthin in blood was at 4 hours after administration, and the plasma concentration is $2.15 \mathrm{nmol} / \mathrm{L}, \mathrm{T} 1 / 26.25 \mathrm{~h}$, and AUC $10.75 \mathrm{nmol} / \mathrm{L} / \mathrm{h}$ Conclusions: The method was applied successfully in a pharmacokinetic study and the resulting oral brown seaweed bioavailability calculated.

Key words: Fucoxanthin, Brown seaweed, Colon cancer.
\end{abstract}

\section{INTRODUCTION}

Fucoxanthin is one of the most abundant carotenoids, especially in the marine environment. It has been reported that fucoxanthin have biological functions, including anticancer, antihypertensive, anti-inflammatory, antioxidant, and anti-obesity; antidiabetic activity; and hepatoprotective. Investigations into absorption, distribution, metabolism, and excretion of fucoxanthin suggested that fucoxanthin hydrolyzed to fucoxanthinol in the gastrointestinal tract by the liver and other digestive enzymes. These results indicate that fucoxanthin is metabolized as fucoxanthinol, the deacetylated form, from the gastrointestinal tract into the systemic circulation in mammals. Fucoxanthin does not appear in mouse plasma after fucoxanthin administered, indicating the absence of the absorption in an animal model, fucoxanthinol, and metabolism of oral fucoxanthin. For further development and rational use of fucoxanthin, it was considered essential to develop a method for quantitative of bioactive fucoxanthin and its derivative in plasma samples. In the present study, mice were administered oral fucoxanthin, and the pharmacokinetic parameters of fucoxanthin observed. This current research might provide preliminary pharmacokinetic information regarding fucoxanthin in AOM-DSS mice for future pharmacology studies.

\section{MATERIAL AND METHODS}

\section{Chemicals}

Ethanol, methanol, acetonitrile (Merck), fucoxanthin standard (Sigma), azoxymethane (AOM) (SigmaAldrich), dextran sulfate sodium (DSS) (SigmaAldrich).

\section{Brown seaweed}

Brown seaweed Turbinaria decurrens was collected from Binuangen Beach, Banten, Indonesia. The collected seaweeds were washed with tap water and distilled water to remove salt, and other debris then packed with ice to keep fresh during the transportation to the laboratory. Fresh seaweed Turbinaria decurrens Bory was extracted with ethanol (70\%) and macerate for $3 \times 24$ hours. The filtrate was evaporated using vacuum evaporator.

\section{AOM-DSS mouse model}

The AOM-DSS mouse model was adopted based on the methods by Wang et al. (2016), with some modifications. Swiss Webster male mice (seven weeks old) were intraperitoneally injected with $\mathrm{AOM}$ at $12.5 \mathrm{mg} / \mathrm{kg}$ body weight. One week after AOM injection, the mice were treated with two DSS cycle, which comprised two steps in which mice were oral 
with $2.5 \%$ (w.v) DSS for five days followed by 16 days of regular water feeding, and then treated with DSS in one more cycle.

All mouse model was treated by brown seaweed Turbinaria decurrens Bory extract $(3.612,7.224,14.448 \mathrm{mg} / \mathrm{mL} 20 \mathrm{~g}$ body weight) from the first induced by AOM, except the normal group. In the last day of treatment, blood were collected into heparin tube, centrifuge at $1000 \mathrm{xg}$ for $15 \mathrm{~min}$ to get the plasma.

\section{Plasma sample preparation}

Preparation procedure was adopted from Zhang et al. (2015) to $100 \mu \mathrm{L}$ of plasma sample in a $1.5 \mathrm{~mL}$ tube, $20 \mu \mathrm{L}$ of fucoxanthin standard solution and $680 \mu \mathrm{L}$ methanol were added and mixed by vortexing for $1 \mathrm{~min}$. After centrifugation at 25,000 $\mathrm{x} g$ for $10 \mathrm{~min}$, the clear supernatant was filtered through a membrane $(0.22-\mu \mathrm{m}$ pore size) and injected into the HPLC system.

\section{HPLC Condition}

HPLC condition used the method as described by Noviendri et al. (2011). HPLC analysis carried out using a Shimadzu system equipped with a pump (LC-20AT), UV/Vis detector (SPD-20A). Reversed-phase HPLC (RP-HPLC) analysis was carried out using a C18 RP column, $5 \mu \mathrm{m}$ particle size, $250 \mathrm{~mm} \times$ 4,6 mm (YMC Co., LTD). Fucoxanthin content was determined with methanol-acetonitrile $(7: 3, \mathrm{v} / \mathrm{v})$ as the mobile phase at a flow rate $0.5 \mathrm{ml} / \mathrm{min}$.

\section{RESULT}

\section{Identification of Fucoxanthin}

Figure 1A showed that Retention time of single compound of Fucoxanthin Standard at 7.905 min. Figure 1B showed that the peak with Rt 7.98 min almost similar to a peak on Fucoxanthin standard came from the ethanolic extract of $T$. decurrens. Figure $1 \mathrm{C}$ showed the chromatogram from normal mouse plasma after fed by ethanolic extracts of $T$. decurrens, the plasma showed fucoxanthin at the similar Rt of Fucoxanthin standard. Figure 1D showed the chromatogram of AOM-DSS mice after fed by ethanolic extract of $T$. decurrens, but the fucoxanthin peak cannot be found on mice model, but another major peak was observed at the Rt $2.5 \mathrm{~min}$. We thought that peak was Fucoxanthinol, the major metabolite of Fucoxanthin.

We then evaluate the plasma by LC-MS/MS and the result as shown in Figure 2.

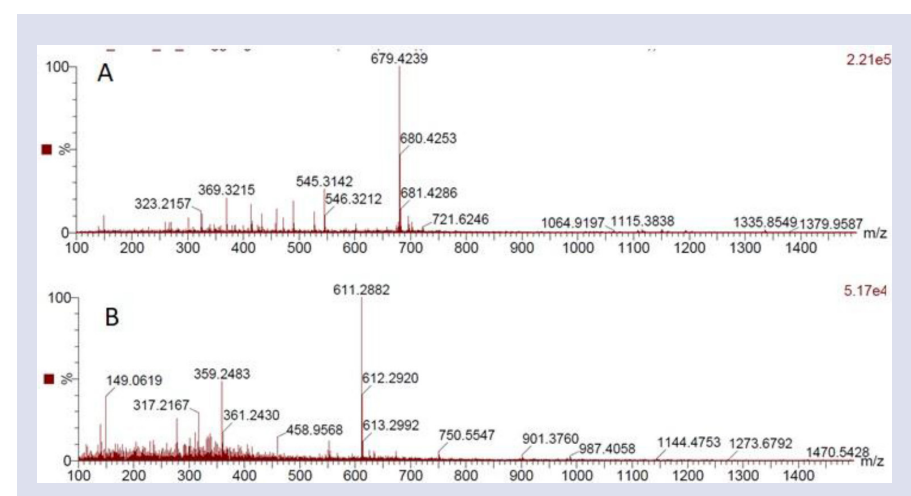

Figure 1: Chromatogram of Fucoxanthin in various conditions. Note: A. Chromatogram of Standard Fucoxanthin; B. Chromatogram of ethanolic extracts of T. Decurrens; C. Chromatogram of Normal Mouse Plasma that feed by ethanolic extracts T. Decurrens; D. Chromatogram of AOM-DSS mice plasma that feeds by ethanolic extracts T. Decurrens.

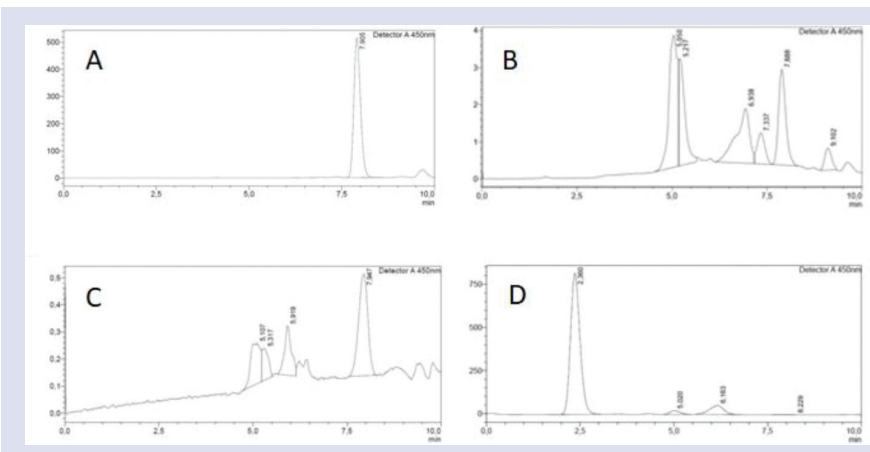

Figure 2: Mass Spec of A. Fucoxanthin. B. Fucoxanthinol.

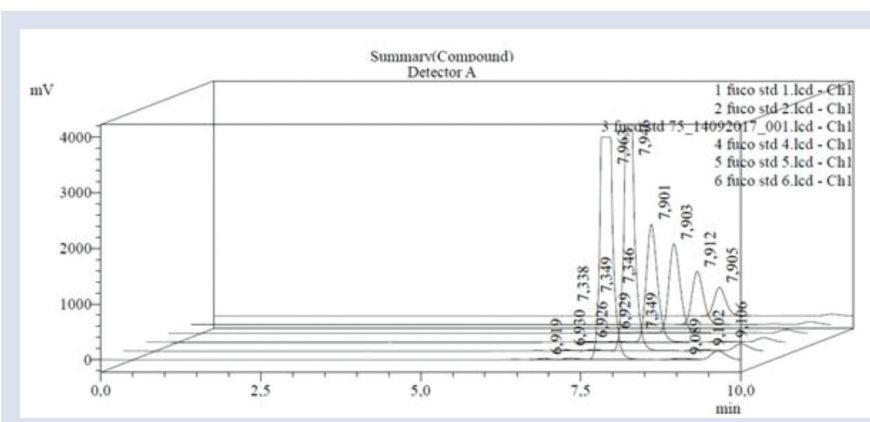

Figure 3: Chromatogram of standard fucoxanthin from $25 \mathrm{ppm}$ to $200 \mathrm{ppm}$.

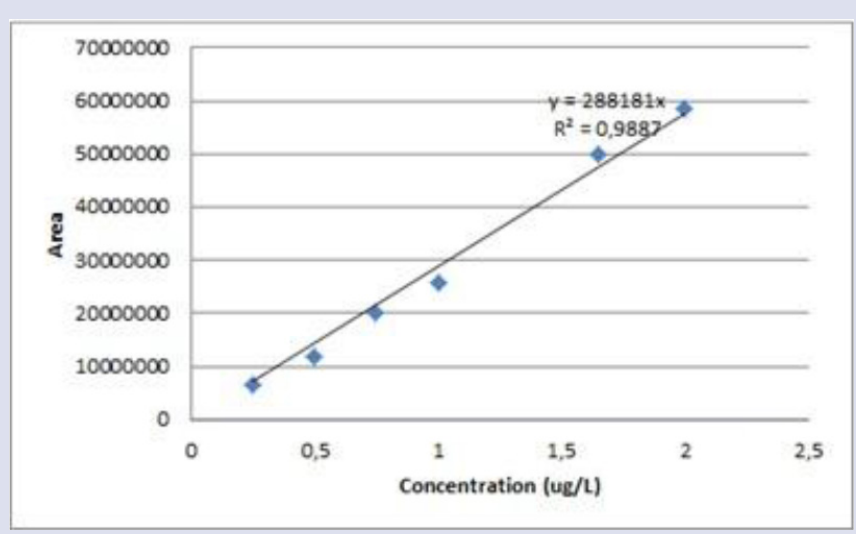

Figure 4: The linearity of Concentration of Fucoxanthin and its area.

\section{METHOD VALIDATION}

\section{Specificity and Selectivity of method}

Specificity and selectivity were assessed by comparing chromatograms of six different batches of blank mouse plasma samples to corresponding spiked plasma samples.

\section{Calibration Curve Linearity}

Standard curves were established by plotting the value of chromatogram peak areas of fucoxanthin as shown in Figure 3 and Figure 4.

\section{Studies of oral Fucoxanthin Administration on AOM-DSS model mouse.}

The profiles of fucoxanthinol after a single dose of fucoxanthin in AOMDSS mouse was shown in Figure 5. 


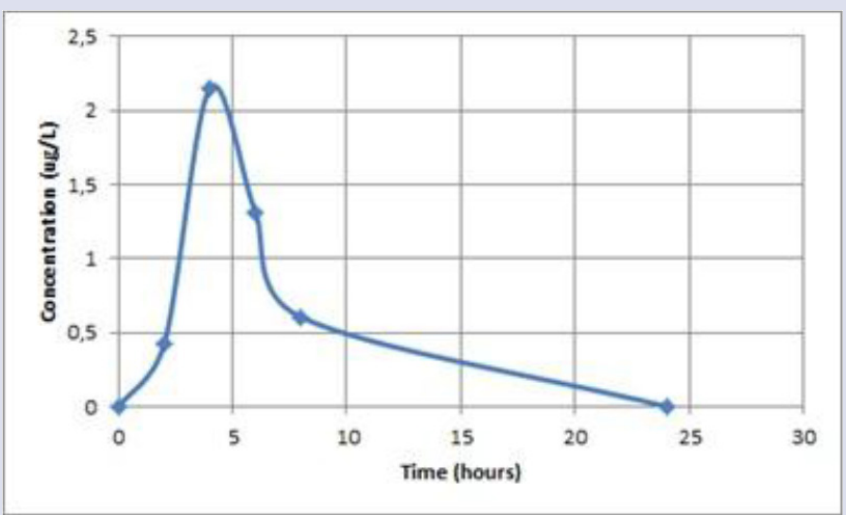

Figure 5: The profiles of fucoxanthinol after a single dose of fucoxanthin in AOM-DSS mouse.

Table 1: Single dose oral Fucoxanthin in AOM-DSS mouse.

\begin{tabular}{cccc}
\hline $\mathrm{T}_{\max }$ & $\mathrm{C}_{\max }$ & $\mathrm{T}_{1 / 2}$ & AUC \\
\hline 4 hours & $2.15 \mathrm{nmol} / \mathrm{L}$ & 6.25 hours & $10.75 \mathrm{nmol} / \mathrm{L} / \mathrm{hour}$ \\
\hline
\end{tabular}

After calculation from Figure 5, we have pharmacokinetics data as shown in Table 1.

\section{DISCUSSION}

In the previous study, we evaluated the effect of fucoxanthin content brown seaweed on AOM-DSS mice. Fucoxanthin content brown seaweed could prevent the development of tumor in that model. Therefore, in the present, we studied the pharmacokinetics of fucoxanthin in the AOMDSS mice.

To this end, we evaluated the Fucoxanthin in the standard solution compare with Fucoxanthin in the ethanolic extract of T. decurrens and on the plasma of normal and AOM-DSS mice that fed by ethanolic extract of T. decurrens. We found as shown in Figure 1A-1C, the peak of Fucoxanthin that has Rt 7,903 as shown in standard, was found in those three samples. But the fucoxanthin in AOM-DSS mice was not found, probably in that model Fucoxanthin was metabolized faster to Fucoxanthinol. Fucoxanthinol has Rt faster than Fucoxanthin. Dietary fucoxanthin was mainly converted to fucoxanthinol. Fucoxanthin metabolites were accumulated in the body at a higher ratio than astaxanthin and were preferentially accumulated in the liver, heart and adipose tissues, suggesting that these tissues are targets of fucoxanthin metabolites.

We then confirmed by LC-MS/MS and found that Fucoxanthin has MS 681.42, whereas Fucoxanthinol has 611,29. This result similar to Hashimoto et al. 2009.

Then we evaluated Pharmacokinetics parameters of Fucoxanthinol in AOM-DSS mice and found that Tmax 4 hours, Cmax $2.15 \mathrm{nmol} / \mathrm{L}, \mathrm{T} 1 / 2$ $6.25 \mathrm{~h}$, and AUC $10.75 \mathrm{nmol} / \mathrm{L} / \mathrm{h}$.

\section{CONCLUSION}

The Pharmacokinetic of ethanolic extract of T. decurrens has Tmax 4 hours, Cmax $2.15 \mathrm{nmol} / \mathrm{L}, \mathrm{T} 1 / 26.25 \mathrm{~h}$, and AUC $10.75 \mathrm{nmol} / \mathrm{L} / \mathrm{h}$.

\section{ACKNOWLEDGEMENT}

This research was funded by Directorate of Research and community Service Universitas Indonesia, 2017.

\section{CONFLICT OF INTEREST}

The authors declare no conflict of interest.

\section{ABBREVIATIONS USED}

AOM: Azoxymethane; DSS: Dextran Sulfate Sodium; RP-HPLC: Reversed-Phase High-Performance Liquid Chromatography; T 1/2: Half life; AUC: Area Under Urve.

\section{REFERENCES}

1. Subaryono, Subaryono. Distribution of brown seaweed producing alginate in Indonesia and the potential utilization. Squalen Bulletin of Marine and Fisheries Postharvest and Biotechnology. 2011;6(2):55-62.

2. Maeda H1, Tsukui T, Sashima T, Hosokawa M, Miyashita K. Seaweed carotenoid, fucoxanthin, as a multi-functional nutrient. Asia Pac J Clin Nutr. 2008;17 Suppl 1:196-9.

3. Kumar SR, Hosokawa M, Miyashita K. Fucoxanthin: A Marine Carotenoid Exerting Anti-Cancer Effects by Affecting Multiple Mechanisms. Marine Drugs. 2013;11(12):5130-47. http://doi.org/10.3390/md11125130.

4. Xia S, Wang K, Wan L, Li A, Hu Q, Zhang C. Production, Characterization, and Antioxidant Activity of Fucoxanthin from the Marine Diatom Odontella aurita. Marine Drugs. 2013;11(7):2667-81. http://doi.org/10.3390/md11072667.

5. Heo SJ, Yoon WJ, Kim KN, Ahn GN, Kang SM, Kang DH, et al. Evaluation of the anti-inflammatory effect of fucoxanthin isolated from brown algae in lipopolysaccharide-stimulated RAW 264.7 macrophages. Food and Chemical Toxicology. 2010;48(8-9):2045-51. https://doi.org/10.1016/j.fct.2010.05.003.

6. Maeda H, Hosokawa M, Sashima T, Murakami-Funayama K, Miyashita K. Anti-obesity and anti-diabetic effects of fucoxanthin on diet-induced obesity conditions in a murine model. Molecular Medicine Reports. 2009;2:897-902. https://doi.org/10.3892/mmr_00000189.

7. Peng J, Yuan JP, Wu CF, Wang JH. Fucoxanthin, a Marine Carotenoid Present in Brown Seaweeds and Diatoms. Metabolism and Bioactivities Relevant to Human Health. Marine Drugs. 2011;9(10):1806-28. http://doi.org/10.3390/ md9101806

8. Zhang $Y$, Wu H, Wen H, Fang H, Hong Z, Yi R. Simultaneous determination of fucoxanthin and its deacetylated metabolite fucoxanthinol in rat plasma by liquid chromatography-tandem mass spectrometry. Marine Drugs. 2015;13(10):6521-36. https://doi.org/10.3390/md13106521.

9. Hashimoto T, Ozaki Y, Taminato M, Das S, Mizuno M, Yoshimura K. The distribution and accumulation of fucoxanthin and its metabolites after oral administration in mice. British Journal of Nutrition. 2009;102(2):242-8. doi:10.1017/ S0007114508199007. 
GRAPHICAL ABSTRACT

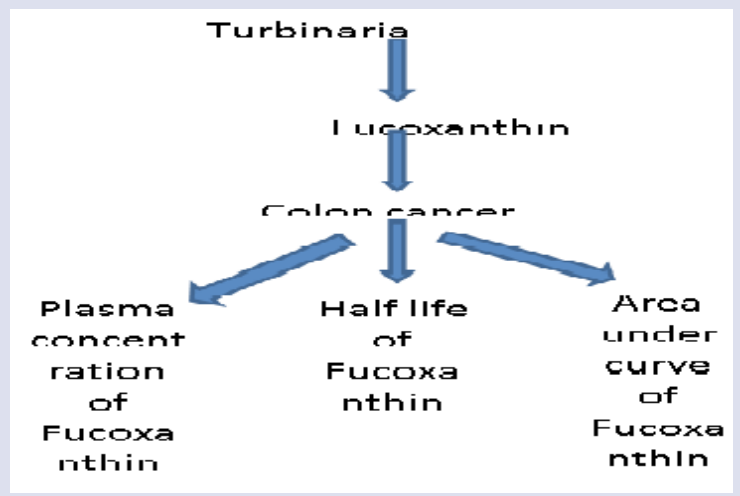

\section{SUMMARY}

Colon Cancer is one of leading cancer that causes morbidity and mortalityworldwide, causes 774,000 deaths. Fucoxanthin contained brown seaweed Bory) extracts showed cytotoxic activity by and study, including colon cancer. This study aims to examine the absorption profile of fucoxanthin in blood plasma on colon cancer model mice. Methods: Mice were induced by azoxymethane (AOM) and two cycle dextran sulfate sodium (DSS). Mice were given an extract of brown seaweed Bory that contain fucoxanthin. Fucoxanthin content in blood plasma analyzed using mobile phase methanol: acetonitrile by Reversed- Phase HighPerformance Liquid Chromatography (RP-HPLC) analysis. Results: The maximum concentration of fucoxanthin in blood was at 4 hours after administration, and the plasma concentration is $2.15 \mathrm{nmol} / \mathrm{L}, \mathrm{T} 1 / 26.25 \mathrm{~h}$, and AUC $10.75 \mathrm{nmol} / \mathrm{L} / \mathrm{h}$ Conclusions: The method was applied successfully in a pharmacokinetic study and the resulting oral brown seaweed bioavailability calculated

\section{ABOUT AUTHORS}

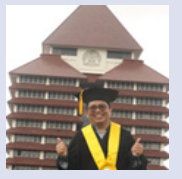

Anton Bahtiar: obtained his Ph. D. degree in 2010 from Nara Institute of Science and Technology, Japan. Currently, He is lecturer and researcher at faculty of pharmacy, Universitas Indonesia since 1998. He is also a head of Pharmacology and Toxicology Laboratory. His research projects are focus on Herbal medicine, and tried to solve the mechanism of action of herbal medicine, especially for osteoporosis and menopouse.

Cite this article: Qurrota'Ayun N, Zakaria AD, Bahtiar A. Preliminary of Pharmacokinetics Study of Brown Seaweed (Turbinaria decurrens Bory) Extract in Colon Cancer Model Mice Induced by AOM (Azoxymethane) and DSS (Dextran Sodium Sulphate). Pharmacog J. 2018;10(3):567-70. 